\section{Tribos URBANAS E IDENTIDADES NAS METRÓPOLES}

\section{Márcia Regina da Costa*}

Resumo: O objetivo do presente artigo é discutir, de um ponto de vista teórico, o tema das tribos urbanas e da constituição das identidades. Inicialmente, partimos da análise que alguns autores fazem da sociedade atual e, posteriormente, retomamos o tema em pauta, realizando um balanço teórico sobre ele. Refletiremos sobre a temática da identidade e das tribos urbanas tendo como suporte as reflexôes, entre outras, de Berman; Balandier; Mafessoli; Giddens; Costa, Tornero \& Tropea; Castells.
PALAVRAS-CHAVE: tribos urbanas; identidades; cultura; globali-

\footnotetext{
*Professora do Departamento de Antropologia e do Programa de Estudos Pós-Graduados em Ciências Sociais da Pontifícia Universidade Católica de São Paulo - PUC-SP.
}

A problemática das tribos urbanas, assim como a constituição das identidades, levanta tanto questóes teóricas quanto aquelas relativas ao tipo de sociedade em que estamos inseridos. E, quando estudamos a nossa sociedade, freqüentemente a denominamos sociedade moderna.

Parte dos autores que aqui utilizaremos argumentam que a modernidade não pode ser analisada como se não comportasse tensões, transformações, desdobramentos internos. Outros ponderam que, na atualidade, os limites da modernidade já teriam sido transpostos em direção a um outro tipo de sociedade.

Berman argumenta que existe um conjunto de experiências vitais que compõe o que ele denomina modernidade. Essas experiências acionam sentimentos de angústia, medo, aventura e, ao mesmo tempo em que esses sentimentos e sensações unificam mundialmente os seres humanos, somos despejados em um cotidiano que, aparentemente, tornou-se incapaz de fornecer parâmetros fixos, coletivos de orientação e de luta. Inspirando-se em Karl Marx, Berman argumenta que "ser moderno é fazer parte de um universo no qual (...) 'tudo o que é sólido desmancha no ar'” (1986: 15). Em sua opinião, estamos imersos na terceira fase da modernidade. Nesta última fase, o processo de modernização abarcou o mun- 
do inteiro e, concomitantemente, acelerou-se a fragmentação existencialmente vivida, até o ponto em que as pessoas perderam a capacidade de atribuir sentido à vida e às atividades. Berman postula que a radicalização da fragmentação da sociedade, imposta pela modernidade nas últimas décadas do século XX, levou as pessoas a buscarem desesperadamente um sentido para suas vidas. Elas e a própria sociedade perderam contato com aquilo que, acreditavam, fazia parte, ainda que imaginariamente, de suas raízes.

Um dos exemplos dessa problemática socialmente vivida foi a reabilitação, nos anos setenta, dos estudos e da luta das minorias pela reconstrução da memória e da identidade étnica como componentes básicos da recomposição das identidades pessoal e coletiva. Não há de se estranhar que, exatamente nessa década, as séries de televisão Raizes, de Alex Haley, e Holocausto, de Gerald Green, tenham alcançado - inicialmente na televisão norte-americana e, posteriormente, na de outros países - audiência tão marcante. Tanto em uma série como na outra foram apresentadas "versōes extravagantemente idealizadas do passado étnico e familiar, em que todos os antepassados são belos, nobres e heróicos - e toda a dor, ódio e confusão derivam de grupos opressores 'externo'". (BERMAN, 1986: 317)

Mas quando emergiu a modernidade? Em Balandier, razão ocidental e modernidade interrogam-se mutuamente e exprimem as tensóes, rupturas, contradiçóes de uma dada sociedade e cultura. Giddens pondera que a modernidade restringiu-se, desde o princípio, a um determinado período histórico, a uma certa organização cultural, socioeconômica e a certos costumes e estilos de vida que emergiram na Europa em torno do século XVII, cujas influências e posteriores desdobramentos se tornaram mundiais. $\mathrm{O}$ autor conclui que o desenvolvimento do Capitalismo foi central na expansão mundial das instituiçôes modernas. Mas, ainda para Giddens, uma das conseqüências da modernidade é o processo de globalização, que introduz novas formas de dependência e interdependência mundial e, além disso, gera um processo de desenvolvimento desigual tanto do ponto de vista econômico quanto social. Um de seus aspectos centrais é que a globalização fragmenta e coordena novas formas de relaçóes sociais e culturais.

Uma questão importante analisada em Giddens é que, se a modernidade emergiu no século XVII, não permaneceu estática e inalterada, mas sofreu uma série de transformações capitaneadas, entre outros processos, pelas transformaçōes do Capitalismo e pela consolidação do processo de globalização que nos estariam levando para a radicalização da modernidade, uma modernidade tardia. A partir 
dessa constatação, alguns autores sustentam que estamos vivendo um momento de transição, ou até mesmo de constituição de uma nova forma de organização social de uma dada sociedade como, por exemplo, a sociedade em rede de Castells.

No debate entre aqueles que defendem que vivemos e caminhamos para o fim ou estamos além-modernidade, encontramos também autores que adotam o termo sociedade pós-industrial ou, no caso de Lyotard (1985), emergência da pós-modernidade. Em sua opinião, com a pós-modernidade temos o fim da fé na possibilidade de um conhecimento histórico e de um desenvolvimento humano planejado. A quebra da crença de que somos seres sociais inseridos numa realidade que nos prende solidamente a um determinado passado, o qual nos permite projetar um futuro previsível, seria, para Lyotard, a evaporação das grandes narrativas. Isso implicaria o declínio da posição central ocupada pelo conhecimento científico e a vitória da multiplicação de formas heterogêneas de conhecimento.

É a percepção dessa nova realidade que levou Balandier a propor que a modernidade exprime uma realidade e uma temporalidade fragmentadas. Ele argumenta que a modernidade acentua o que é imediato, atual, efêmero e nos chama a atenção para os fenômenos que se inscrevem no instante e no presente. Estamos inseridos num cotidiano em que se recusa o que é construído, pois a preferência é pela criação fragmentada, heteróclita, precária. A modernidade, além de desenraizar os indivíduos, faz o mesmo com sua produção social e cultural. Dessa maneira, a lógica da modernidade opera de forma difusa no cotidiano.

A questão é que, em Balandier, no extremo de sua concepção de modernidade, estabelece-se contato com a noção de pós-modernidade visualizada por Maffessoli. Segundo este autor, a pós-modernidade institui um novo paradigma estético e pontua o fim de uma lógica individualista típica da modernidade, de um Eu fechado sobre si mesmo. Caminharíamos, então, em direção à persona e à multiplicidade de papéis e máscaras em que a pessoa só existiria em termos do papel ou máscara usada em dado momento e situação. Temos, em Mafessoli (1987: 17), uma afirmação do apogeu das massas e do declínio do proletariado enquanto sujeito histórico e "assistimos tendencialmente à substituição de um social racionalizado por uma socialidade com dominante empática”.

Balandier argumenta que a noção de indivíduo é um dos produtos da constituição da modernidade. Todavia, tradicionalmente, o indivíduo teve a cidade, o trabalho e a instrução como marcas de uma modernidade sentida como 
triunfante. Mas os desdobramentos dessa mesma modernidade subverteram essas marcas e aprisionaram o indivíduo em uma razão instrumental e nas malhas de uma burocratização crescente da sociedade, além de submetê-lo aos poderes da mídia e da sociedade de consumo. A cidade, dentro dessa nova expressão da modernidade, não é mais tida como o locus da liberação do indivíduo das malhas de uma sociedade tradicional e opressiva "a cidade torna-se culpada do fechamento e isolamento que aliam multidão e solidão (...) não há mais encantamento, mas seu contrário" (BALANDiER, 1997: 61). Nessa sociedade, segundo Canetti (1995), o indivíduo vive imerso no pavor do contato com o desconhecido, com o estranho e, já que não pode desvencilhar-se de tal sentimento, busca abrigo na massa.

Portanto, Balandier (1997: 61) afirma que a sociedade de massas produz um 'nivelamento narciso-mediático' nos indivíduos. Esse nivelamento relacionase, em sua opinião, tanto à "lógica da sociedade de consumo - onde também o homem torna-se pronto para ser consumido, porque entregue a uma 'ordem canibal' - quanto à lógica da política onde operam fatores do totalitarismo" (p. 142). Todas essas incertezas afetam não apenas a formação do Eu, mas também a sua constituição em relação ao Outro.

Os dilemas da constituição de um individualismo moderno sitiado e moldado por uma sociedade de massas foram problematizados por Lasch. Nessa sociedade cindida por problemas e temores de toda a natureza, o Eu se organiza e se contrai defensivamente para sobreviver diante da adversidade. Segundo o autor, o individualismo moderno é fruto de um Eu inseguro, sitiado, mínimo, narcisista, "que ora almeja reconstruir o mundo à sua própria imagem, ora anseia fundir-se em seu ambiente numa extasiada união (...) A identidade tornou-se incerta e problemática, não porque as pessoas não ocupem mais posiçốes sociais fixas (...) mas porque elas não mais habitam um mundo que exista independentemente delas" (1986: 12-23). Para Lasch, as preocupaçōes existentes na atualidade referente à busca das identidades, sejam estas pessoais ou coletivas, revelam as nossas incertezas quanto à constituição da individualidade dentro de uma modernidade organizada em torno do consumo de massas, que fragiliza as pessoas e as torna dependentes, incapazes de compreender e de enfrentar o mundo.

Lasch afirma que, de fato, na sociedade de massas a identidade torna-se incerta e problemática. Todavia, isso não decorre do fato de as pessoas não mais ocuparem posições sociais fixas, e sim porque elas estão inscritas em um mundo estilhaçado 
pelo consumo de massas, não se situando de forma independente no mundo circundante.

Para Balandier, os dilemas da identificação incerta e problemática, típicos de uma sociedade pós-industrial, denunciam exatamente os efeitos das mudanças profissionais bruscas, impulsionadas pelos brutais efeitos da tecnologia e da informática. Destaque-se ainda a imprecisão dos papéis sociais que resulta na fragmentação das relações com o Outro e também na multiplicação de máscaras ou aparências das quais se reveste o indivíduo em uma sociedade de comunicação, que imprime sua marca por meio de novos signos e símbolos.

Portanto, a identidade torna-se incerta e problemática dentro de uma sociedade fragmentada e em crise de legitimidade. Dessa maneira, os papéis sociais tornam-se imprecisos e confusos devido, entre outros fatores, à multiplicação das redes de comunicação que permitem ao indivíduo tornar-se plural e simultaneamente conectado a vários papéis. Balandier argumenta que o termo 'tribo' é freqüentemente usado para se referir às diversas formas de associaçôes - clubes, comunidades, redes - resultantes do processo social de fragmentação e do concomitante processo de reagrupamento associativo e tribal.

Nesse cenário descrito como típico da pós-modernidade, também encontramos pontos de contato com o pensamento de Maffesoli, quando este postula que as tribos exprimem a 'socialidade fundante' de nossa atualidade, na qual ocorre

... o vaivém constante que se estabelece entre a massificação crescente e o desenvolvimento de microgrupos que chamarei de tribos. Claro está que, como as massas em permanente agitação, as tribos que nela se cristalizam são instáveis. As pessoas que compóem essas tribos podem evoluir de uma para a outra (...) ao contrário da estabilidade induzida pelo tribalismo clássico, o neotribalismo é caracterizado pela fluidez, pelos ajuntamentos pontuais e pela dispersão. $\mathrm{O}$ adepto do jogging, o punk, o look rétro, os 'gente-bem', os animadores públicos nos convidam a um incessante travelling. (...), a efervescência do neotribalismo que, sob as mais diversas formas, recusa reconhecer-se em qualquer projeto político, não se inscreve em nenhuma finalidade e tem como única razão ser a preocupação com um presente vivido coletivamente. (1987: 8-9, 105-107)

A massa ultrapassa a lógica identitária, seja ela sexual, individual ou nacional. 
Costa, Tornero \& Tropea postulam que a análise de Mafessoli é fecunda e deve ser utilizada na pesquisa dos bandos, grupos de jovens e adolescentes que emergem nas grandes cidades contemporâneas. Em sua análise, também é adotada a noção de tribos urbanas para denominar esses tipos de agrupamentos juvenis. $\mathrm{O}$ tribal surge como uma espécie de compensação diante de uma sociedade cujos laços e coesão social são frágeis Este 'neotribalismo' exemplificaria as formas contemporâneas de sociabilidade desenvolvidas por grupos de jovens nesse fim/início de milênio. $\mathrm{O}$ neotribalismo juvenil corresponderia a uma espécie de resposta a uma sociedade fragmentada, fria, individualista, competitiva e burocrática. A vivência no interior das tribos abria aos jovens a possibilidade de um encontro afetivo, passional, criação de um espaço de dissidência e de um canal simbólico de expressão identitária.

Os autores em pauta consideram como 'segunda modernidade' o que Maffessoli denomina pós-modernidade. Ponderam que o fenômeno da neotribalização juvenil não existe à margem da divisão de classes ou das contradições entre grupos sociais, mas sua especificidade está exatamente em ser interclassista e situar-se no âmbito de comunicabilidade dessas classes e grupos (COSTA, Tornero \& TropeA, 1996: 37). Essas tribos ostentam um vitalismo rebelde, opõem-se ao individualismo moderno e almejam situar-se à margem das normas da sociedade.

Mas Costa, Tornero \& Tropea, ao estudarem os mecanismos de produção de identidades na atualidade, levam também em consideração algumas ponderações de Giddens. A modernidade impulsionada pelo processo de globalização separa o espaço do lugar ${ }^{1}$. Em substituição, instaura um espaço abstrato, neutro, esvaziado de referências culturais próprias, que não serve mais de suporte para a elaboração da forma como a identidade era tradicionalmente produzida. As pessoas, da mesma forma que a economia e a cultura, também se globalizam e cada vez menos estão inscritas e referidas a um espaço e lugar concretos.

No entanto, os autores acreditam que o espaço externo, com suas barreiras e fronteiras culturais, tenha-se transformado em termos da construção da identidade, ocorrendo o seu deslocamento para um espaço interno, recriado social, simbólica e imaginariamente. Neste fim/início de milênio, assistimos à substituição gradativa dos limites e fronteiras externas - que serviam de referente e limite à construção da identidade - por algo que se deslocou para dentro. $\mathrm{O}$ inimigo, opositor externo que tradicionalmente vinha de fora, punha em perigo as fronteiras e devia ser 
combatido externamente para não ultrapassasr os limites da cidadela, tornou-se o repúdio e o ódio ao diverso, ao diferente. E da guerra externa passou-se ao repúdio daquilo que põe em perigo, imaginariamente, a estrutura psíquica e a recriação desse espaço interno do indivíduo. $\mathrm{Na}$ atualidade, nossa sociedade urbana, em vez de dissolver as fronteiras, acaba por recriá-las de modo fragmentado, produzindo barreiras simbólicas internas, forjando processos identitários regados de um vazio, de uma nostalgia do passado devido à perda - freqüentemente também imaginária - de valores tradicionais. É assim que devemos entender como vivemos em um mundo que recria formas de racismo, xenofobia e de repúdio ao diferente.

Este mundo também pode ser percebido quando analisamos, segundo os autores, o caso das facçôes mais violentas, xenófobas, neonazistas de tribos de jovens como no caso dos skinheads ${ }^{2}$. Esta constatação questiona o fato de Maffessoli considerar que, em geral, o neotribalismo recusa o posicionamento político e não se inscreve em nenhuma finalidade explícita. Os skinheads de tendência neonazista, mesmo que não possuam objetivos e um projeto político totalmente claro e coerente, expressam e se filiam a correntes sociais e políticas que primam pela xenofobia, pelo apoio a atitudes autoritárias e até por aproximações mais ou menos claras com as correntes políticas de extrema-direita.

Costa, Tornero \& Tropea também se questionam sobre a validade da noção de tribos, presente na sociedade urbana contemporânea, para a análise de determinados fenômenos. Eles argumentam que muitos antropólogos se recusam a tal utilização no contexto urbano na medida em que, nesta situação, não existiria um tipo de cultura e sociedade característico das tribos primitivas. Ao mesmo tempo, poderíamos correr o risco de transformar a pesquisa na apreensão de algo exótico e diferente do universo cultural e social do observador. Aliás, a mídia e os meios de comunicação contribuem para a difusão desse exotismo desde que ele auxilie na ampliação do mercado e da audiência.

Mas os autores acreditam na fecundidade de se trabalhar com tal noção. Assim, abre-se um novo problema relativo ao fato de saber, nos limites de uma dada pesquisa, o que é uma tribo urbana. Esse problema pode ser em parte solucionado ao "reconstruirmos o discurso social sobre as 'tribos'. Nesse ponto, vamos encontrar muitos elementos de dispersão que complicam a nossa tarefa” (CosTA, Tornero \& Tropea, 1996: 92-93). Entre eles, inicialmente teríamos o fato de que a definição e percepção das diferenças existentes entre as diversas tribos são de
${ }^{2} \mathrm{O}$ s skinheads surgiram na Inglaterra em fins dos anos sessenta e, posteriormente, o grupo espalhou-se por vários países. 
difícil apreensão, inclusive para os membros de tribos rivais. Elas variam e estão em mutação constante, sendo que "a irrelevância estatística do fenômeno não pode ser uma razão para desconsiderar sua importância qualitativa.(...) muitos dos grupos pretensamente presentes no cenário urbano constituem mais uma recordação (uma recordação de uma presença passada) do que uma presença quantitativa real”. (op. cit.: 94-95)

Outro fator é que os meios de comunicação ocupam um papel importante na construção social do fenômeno tribo, na sua multiplicação e dispersão pela metrópole, criando, inclusive, denominações que serão adotadas por seus integrantes. Não apenas os meios de comunicação ocupam um papel na produção e reprodução da realidade, mas também as formas de divulgação de caráter alternativo ao sistema utilizado por esses grupos. Os autores citam, especificamente, os fanzines e qualquer outro tipo de material produzido no seio das diversas tribos e que circulem interna e externamente aos grupos; acreditam que exerçam papel importante na difusão das tribos, cristalizando determinadas realidades de natureza cultural e social. Devemos agregar a esta análise o papel exercido pela indústria cultural ao gerar uma série de produtos e bens, inclusive de natureza simbólica, que são capazes de promover essa cristalização. Além disso, não devemos descartar os produtos culturais provenientes das próprias tribos, como no caso das bandas, suas músicas e seus diversos estilos.

Como pudemos observar, autores como Balandier, Maffesoli e Costa, Tornero \& Tropea aceitam, ainda que com algumas diferenças na forma como apreendem a sociedade, a noção 'tribo urbana' para caracterizar determinados fenômenos sociais. Os autores também refletem sobre os dilemas da identidade. Mafessoli, ao propor a sua noção de pós-modernidade, chega a afirmar que nela teríamos o predomínio da massa e a ultrapassagem da lógica identitária.

\section{II}

Nesta parte do artigo, retomaremos a análise de Giddens a respeito da globalização e seus desdobramentos no cotidiano individual e coletivo. Aprofundaremos ainda parte do pensamento de Castells sobre sua concepção de sociedade em rede e os concomitantes 
processos de construção de identidade. Ao final, julgamos ser possível recolocar, tendo como parâmetro estes dois últimos autores, a questão das tribos urbanas.

Giddens acredita que, em vez da pós-modernidade, estejamos em um momento de radicalização das conseqüências da própria modernidade, uma modernidade tardia. As principais características dessa radicalização seriam o fim de uma perspectiva unilinear e teológica do desenvolvimento histórico e de uma visão tradicional do conhecimento científico, e também o colapso da crença da posição privilegiada do Ocidente em relação a outras sociedades e culturas.

Em Giddens, uma das fontes dominantes do dinamismo da modernidade é a separação entre tempo e espaço e o desenvolvimento de mecanismos que o autor denomina de 'desencaixe'. Este mecanismo retira a atividade social dos contextos e espaços culturalmente localizados e reorganiza as relações sociais por meio de grandes distâncias espaciais e temporais. As instituiçôes desencaixadas, típicas do processo de globalização, organizam o cotidiano das pessoas, ligando práticas sociais e culturais locais com relaçôes sociais globalizadas. A noção de desencaixe é completada pelo autor com a de 'reencaixe'. Segundo esta noção, as relações desencaixadas são remodeladas parcialmente ou momentaneamente nas condições locais de espaço e tempo.

Graças a essas observações, Giddens pensa a problemática da identidade. Ele pondera que o tecido social, o cotidiano, o familiar, a esfera do privado e a própria intimidade das pessoas são formas remodeladas sob o impacto das tendências globalizantes. Assim,

... com a globalização acelerada dos últimos cinqüenta anos mais ou menos, as conexôes entre vida pessoal do tipo mais íntimo e mecanismos de desencaixe se intensificaram (...) É um equívoco ver o mundo moderno onde grandes sistemas impessoais engolem crescentemente a vida pessoal. Mas não se trata simplesmente de uma diminuição da vida pessoal em prol de sistemas impessoalmente organizados - mas de uma transformação genuína da própria natureza do pessoal. (BERMAN, 1986: $122-123,142$ )

Um exemplo ilustrativo do autor é com relação ao shopping center. Apesar de estarmos cientes de que o seu projeto arquitetônico se liga a uma forma mais ou menos definida mundialmente e que muitas de suas lojas pertencem a grandes 
cadeias, estamos acostumados e familiarizados com ele ao ponto de não sentirmos mais uma sensação de estranhamento e insegurança em suas dependências quando percorremos seu espaço. $\mathrm{Na}$ opinião do autor, isso refletiria não um estranhamento do local, mas a "integração no interior de 'comunidades' globalizadas de experiência partilhada”. (GIDDENS, 1991: 142)

Assumindo que no mundo moderno temos uma transformação da intimidade, Giddens critica a concepção de outros autores quando se referem ao Eu mínimo, sitiado, caso de Lasch. Pondera que, de fato, existe uma preocupação defensiva, de sobrevivência deste Eu diante de um futuro problemático, repleto de riscos e indefinido. Entretanto argumenta, a partir da análise sobre o impacto da globalização na vida cotidiana e da transformação decorrente da intimidade, que existe uma apropriação pragmática e uma atuação até positiva, em alguns casos, desse Eu em relação ao mundo. Esta proposição de Giddens também questiona, em nossa opinião, parte da postura de Balandier, ou mesmo de Maffesoli, com referência à construção da identidade na modernidade, conforme exposto na primeira parte do presente artigo.

Castells também se debruçou sobre a análise dos traços distintivos do capitalismo que se projetam para o início do novo milênio. Ele encontra no paradigma tecnológico (na informação), os princípios organizadores de um novo 'modo de desenvolvimento', que não substitui o modo de produção capitalista, mas lhe dá nova forma e especificidade.

Para o autor, isso nos leva a uma nova estrutura social que é

... caracterizada pela globalização das atividades econômicas (...) por sua forma de organização em redes; pela flexibilidade e instabilidade do emprego e a individualização da mão-de-obra: por uma cultura de virtualidade real construída a partir de um sistema onipresente, interligada e altamente diversificada. E pela transformação das bases materiais da vida - o tempo e o espaço - mediante a criação de um espaço de fluxos e de um tempo intemporal como expressóes das atividades e elites dominantes. (1999: 17)

Um dos desdobramentos de toda essa proposição sobre a nova estrutura social existente transparece na questão da cultura de virtualidade real e criação de um espaço de fluxos como atividade das elites dominantes. Castells define o espaço de 
fluxos como "a organização material das práticas sociais de tempo compartilhadas que funcionam por meio de fluxos" (1999: 436). O autor acrescenta que devemos ter em mente que a sua definição de espaço de fluxos não significa serem estas "práticas sociais de tempo compartilhadas" dependentes da contigüidade física. Para Castells, o espaço reúne práticas sociais que se dão de maneira simultânea no tempo. Em sua opinião, pelas atividades das elites cosmopolitas, o espaço ocupa um papel fundamental neste mecanismo de dominação na medida em que as elites são cosmopolitas. Já as massas são locais, segmentadas e, em princípio, desorganizadas. Entretanto, ele assinala que esta dominação social "provém do fato de os códigos culturais estarem embutidos na estrutura social, de tal forma que a posse desses códigos abre o acesso à estrutura de poder sem que a elite precise conspirar para impedir o acesso às suas redes”. (1999: 440)

A manifestação espacial de dominação dentro do espaço de fluxos apresentase, principalmente, sob duas formas que atuam simultaneamente. Em primeiro lugar, as elites constituem uma verdadeira subcultura, "comunidades simbolicamente segregadas" ( CASTELls, 1999: 440). O autor propõe a hipótese de que "o espaço de fluxos é formado de microrredes pessoais que projetam seus interesses em macrorredes funcionais em todo o conjunto global no espaço de fluxos" (op. cit.: 441); em segundo, como signo de distinção para as elites na sociedade informacional, é a criação de "um estilo de vida e de projetar formas espaciais para unificar o ambiente simbólico da elite em todo o mundo, conseqüentemente substituindo a especificidade histórica de cada local”. (id., ibid.)

Temos, dentro dessa linha de raciocínio, a construção de determinados espaços que estão preferencialmente abertos para essa elite cosmopolita e são relativamente segregados para o restante da população como, por exemplo, os restaurantes, aeroportos e hotéis internacionais, toda uma estrutura de comunicação e informação à disposição 24 horas por dia, assim como um serviço especial de infra-estrutura, apoio e diversão. Ciente desses fenômenos, o antropólogo Marc Augé (1994), apesar de toda uma especificidade teórica, assinalou a existência do não-lugar como uma das características do que denominou supermodernidade. O não-lugar é oposto ao espaço personalizado, ao lar, apesar de Augé concordar que existem conexões entre ambos; o não-lugar é representado por espaços supermodernos de rápida circulação como rodovias, aeroportos e grandes cadeias de

lojas e supermercados que seguem padróes internacionais. Os viajantes e usuários 
preferenciais desses não-lugares podem ter acesso ou distinguir-se pelo uso de símbolos como passaporte, travelers cheques, cartão de crédito internacional, bilhete de avião, entre outros, que autorizam o acesso, os deslocamentos impessoais e comprovam uma determinada identidade.

As elites, segundo Castells, ao "definirem suas comunidades como uma subcultura em rede interpessoal ligadas ao espaço" (1999: 441), afirmam-se e diferenciam-se por um estilo de vida cosmopolita que ultrapassa as fronteiras culturais das sociedades locais. Dessa maneira, a adoção de determinadas dietas de alimentação do $s p a$, terapias orientais e academias de ginástica com padrão internacional, o uso do laptop, a tv a cabo, a preocupação com a comunicação on line, o uso do inglês como idioma preferencial para as transaçôes e contatos, um determinado tipo de vestimenta, "tudo isso são símbolos de uma cultura internacional cuja identidade não está ligada a nenhuma sociedade específica, mas aos membros dos círculos empresariais da economia informacional em âmbito cultural global". (op. cit.: 442)

Castells pondera que é relevante a análise de Giddens referente à construção da identidade na modernidade, que este autor denomina modernidade tardia. Mas seguindo sua linha teórica, na sociedade em rede emergem novos processos para a construção de identidade e de constituição de sujeitos como um "prolongamento da resistência comunal" (1999: 28). Esta resistência situa-se na organização das elites. A busca das identidades, ainda que seja conflitante e problemática em alguns casos, é considerada, pelo autor, uma força atuante contra os processos de homogeneização sociocultural e as desesperanças impostas pela globalização e suas conseqüências na vida das pessoas.

A caracterização que o autor faz do modo capitalista nesse fim/início de milênio permite que possamos nos direcionar para alguns dos desdobramentos presentes em nossa sociedade. A sua análise chama à percepção de que, além da revolução tecnológica e da transformação do Capitalismo, assistimos, desde o fim do século XX, à expansão de novas formas de expressão de identidade coletiva, que desafiam tanto a globalização quanto o cosmopolitismo por meio da afirmação da especificidade cultural e pela busca do controle sobre suas próprias vidas e ambientes. Naturalmente, a afirmação da singularidade e identidade implica uma recriação imaginária constante que aciona, entre outros fatores, uma verdadeira 
bricolagem cultural com a participação de elementos de natureza díspares que são frutos ou consequiências do próprio processo de globalização e de seus avanços tecnológicos.

Entre esses movimentos identitários o autor aponta aqueles que desenvolvem uma prática politicamente renovadora diante do Estado e do processo de globalização. E ainda aqueles de caráter defensivo que se opõem às políticas do Estado-Nação, especialmente os de caráter universalista que buscam beneficiar grupos considerados perseguidos e/ou marginalizados socialmente, mormente nos países do primeiro mundo. Esses movimentos são, em alguns casos, conservadores, excludentes e erguem suas barricadas em defesa de Deus, da etnia, da nação, da região, da família ou outra categoria social e cultural considerada fundamental para um determinado grupo.

Castells também defende a idéia de que não existem movimentos que em si mesmos sejam bons ou maus, progressistas ou retrógrados, mas que todos eles refletem o que é nossa sociedade e ainda podem assinalar para possíveis caminhos de transformação social. Alguns dos exemplos do autor são: o movimento zapatista do México, que o autor denomina primeiro movimento de guerrilha informacional, com a brilhante utilização da mídia e da Internet; a Milícia norte-americana e o Movimento Patriótico dos anos noventa em luta contra o que denominam 'nova ordem mundial' - os quais, graças à Internet, foram baseados no ódio de maior crescimento e também se tornaram conhecidos graças ao atentado em Oklahoma City; finalmente, a seita japonesa Verdade Suprema, que se notabilizou internacionalmente pelo atentado ao metrô de Tóquio com o gás sarim. Todos os movimentos, respeitadas suas especificidades, estão em oposição a um inimigo: os agentes de uma nova ordem econômica e social, que irão destruir e subjugar todos os povos. Assim, cada um deles será contra esse inimigo na defesa de sua identidade específica.

Outro exemplo citado por Castells é sobre as novas formas assumidas pela criminalidade global e sua articulação com a identidade. Para o autor, "quanto mais o crime se globaliza, tanto mais seus componentes (...) valorizam sua identidade cultural, com o objetivo de não desaparecer no turbilhão do espaço de fluxos. Ao fazê-lo preservam suas bases étnicas, culturais e, sempre que possível, territoriais (...) Não obstante, o maior impacto cultural das redes criminosas globais sobre as sociedades em geral, além da expressão de sua identidade cultural, é a nova cultura que 
elas induzem" (1999: 242-243) como uma dos modos de expressão da cultura do hiperindividualismo comunal. Segundo ele, "individualismo porque na cultura da recompensa imediata somente o indivíduo pode ser o padrão da medida. Comunalismo porque para que esse hiperindividualismo se torne uma identidade (...) necessita de um ambiente de valorização e apoio mútuo" (op. cit.: 83). Essa cultura pontifica a exaltação de um determinado tipo de comportamento e de visão de mundo em que a busca do prazer é o parâmetro último, a exaltação do consumo, do imediatismo, da ausência de limites ou submissão a qualquer regra social.

Paralelamente, temos a nova cultura produzida dentro dos guetos urbanos, onde se cristalizam experiências compartilhadas e novas formas de exclusão coletiva. Em seu interior, a questão étnica articula-se e até se sobrepõe aos novos vínculos gerados como o fato de se pertencer a uma mesma gangue territorial, de se estar inserido na economia do crime e da droga, de usar a violência como estilo de vida ou sobrevivência, a experiência comum da opressão policial e da prisão, das escolas sucateadas, de se pertencer a famílias desestruturadas, de habitar em moradias precárias, entre outras. Um dos ícones desses guetos do novo milênio é o rap como um dos porta-vozes de uma cultura produzida em seu interior e que se materializa nas áreas deterioradas das cidades em todo o mundo.

A partir da análise de parte das propostas teóricas de Giddens e Castells, podemos perceber que eles não trabalham explicitamente com a noção de tribo urbana como fazem Maffesoli ou Costa, Tornero \& Tropea. Entretanto, no caso de Castells, podemos admitir, com cuidado, que as elites não deixam de constituir uma espécie de tribo cosmopolita. Mesmo nos guetos urbanos do início do milênio, a cultura se materializa por meio de grupos, gangues - e em tribos -, sendo possível utilizar os referenciais teóricos de Giddens como alavanca explicativa da realidade e recolocar a noção de tribos urbanas sob o seu poder de análise. Naturalmente, esta utilização significaria usar o termo tribos urbanas descolado, em grande parte, da análise de um autor como Maffesoli. Pensamos que balanços sobre a fecundidade analítica ou não de tal noção devem estar referenciados em trabalhos de pesquisa.

ABSTRACT: This article aims to face the issue of urban tribes and the construction
KeY wORDS: urban tribes; identities; culture; globalization. 
of identities. The text starts from analyses made by different authors about the society we are part of and goes on by a theoretical assessment of the issue. Among others, are used contributions of Berman, Balandier, Mafessoli, Giddens, Costa, Tornero \& Tropea e Castells.

\section{REFERÊNCIAS BIBLIOGRÁFICAS}

Augé, MARC. Não lugares: introdução a uma antropologia da supermodernidade. Campinas: Papirus, 1994.

Bal andier, Georges. O contorno: poder e modernidade. Rio de Janeiro: Bertrand Brasil, 1997.

Ber man, Marshall. Tudo que é sólido desmancha no ar: a aventura da modernidade. São Paulo: Companhia das Letras, 1986.

Canet ti, Elias. Massa e poder. São Paulo: Companhia das Letras, 1995.

Cast ells, Manuel. A era da informação: economia, sociedade e cultura. São Paulo: Paz e Terra, 1999-2000. 3 v.

Costa, Pere-Oriol, Tor nero, José Manuel Pérez \& Tropea, Fabio. Tribus urbanas - El ansia de identidade juvenil: entre el culto a la imagem y la autoafirmacion a través de la violencia. Buenos Aires: Paidós, 1996.

Giddens, Anthony. As conseqüências da modernidade. São Paulo: Ed. Unesp 
E
C
C
O
S
R
E
V.
C
I
E
N
T.
n. 1
v. 3

jun.
2001

56 